\title{
Fructose and metabolic diseases: New findings, new questions
}

\author{
Luc Tappy M.D., ${ }^{\mathrm{a}, \mathrm{b}}$, Kim A. Lê Ph.D. ${ }^{\mathrm{a}}$, Christel Tran M.D. ${ }^{\mathrm{a}}$, Nicolas Paquot M.D. ${ }^{\mathrm{c}}$ \\ ${ }^{a}$ Department of Physiology, University of Lausanne, Lausanne, Switzerland \\ b Service of Endocrinology, Diabetes and Metabolism, CHUV, Lausanne, Switzerland \\ ' Service of Diabetology CHU Sart Tilman, Liège, Belgium
}

\begin{abstract}
There has been much concern regarding the role of dietary fructose in the development of metabolic diseases. This concern arises from the continuous increase in fructose (and total added caloric sweeteners consumption) in recent decades, and from the increased use of high-fructose corn syrup (HFCS) as a sweetener. A large body of evidence shows that a high-fructose diet leads to the development of obesity, diabetes, and dyslipidemia in rodents. In humans, fructose has long been known to increase plasma triglyceride concentrations. In addition, when ingested in large amounts as part of a hypercaloric diet, it can cause hepatic insulin resistance, increased total and visceral fat mass, and accumulation of ectopic fat in the liver and skeletal muscle. These early effects may be instrumental in causing, in the long run, the development of the metabolic syndrome. There is however only limited evidence that fructose per se, when consumed in moderate amounts, has deleterious effects. Several effects of a high-fructose diet in humans can be observed with high-fat or high-glucose diets as well, suggesting that an excess caloric intake may be the main factor involved in the development of the metabolic syndrome. The major source of fructose in our diet is with sweetened beverages (and with other products in which caloric sweeteners have been added). The progressive replacement of sucrose by HFCS is however unlikely to be directly involved in the epidemy of metabolic disease, because HFCS appears to have basically the same metabolic effects as sucrose. Consumption of sweetened beverages is however clearly associated with excess calorie intake, and an increased risk of diabetes and cardiovascular diseases through an increase in body weight. This has led to the recommendation to limit the daily intake of sugar calories.
\end{abstract}

Pure, white, and deadly: the dark side of sugar was suspected many years ago, when an association between sugar consumption and coronary heart diseases was recognized and emphasized by John Yudkin [1]. Sugar, a natural sweetener obtained from either sugar cane or beets, is a disaccharide composed of one glucose molecule linked through an $\alpha 1-4$ glycoside bond to a fructose molecule. Fructose, besides contributing to half the total content of sugar, can also be found as a hexose in fruits and honey. More recently, sweeteners started to be produced from corn through starch isolation and hydrolysis to glucose, followed by enzymatic isomerization of part of the glucose into fructose [2,3]. The resulting mixture, known as high-fructose corn syrup (HFCS), has several industrial advantages over sugar, the most important being its low price, and has progressively replaced sugar consumption in North America over the past 30 years.

Fructose metabolism has been reviewed extensively elsewhere [4-6] and will be only briefly outlined here. In the gut, fructose is transported by specific transporters, GLUT5 $[7,8]$. In some subjects, fructose absorption is quantitatively limited, and some malabsorption occurs when large amounts of fructose are ingested. This can cause abdominal discomfort and diarrhea, and production of volatile fatty acids from colonic fructose fermentation $[9,10]$. Fructose absorbed from the gut into the portal vein is nearly completely metabolized in the liver through metabolic pathways distinct from those of glucose; furthermore, the initial steps of its metabolism are insulin-independent, and hence, fructose is largely metabolized without requiring insulin secretion and without increasing plasma glucose. This is due to the fact that 1 ) part of the fructose appears to be directly metabolized in enterocytes, where it is converted and into lactate and glucose, and 2) the bulk of absorbed fructose is taken up by liver cells, where it is rapidly converted into fructose 1-phosphate and triose-phosphates through the sequential actions of fructokinase and aldolase B and triokinase. Fructokinase and aldolase B are not inhibited by ADP and citrate and hence are not regulated by the cellular energy status. In that, fructose differs from glucose, because the ADP and citrate concentrations exert a negative feedback control on the initial steps of glycolysis. As a consequence of this absence of feedback inhibition, virtually all the fructose ingested with a meal (whether under its pure, unbound form, or bound to glucose in sucrose) is rapidly converted into hepatic triose-phosphates [11]. These substrates are subsequently oxidized within the liver cells or converted into glucose and lactate to be released into the bloodstream, or converted into hepatic glycogen. A small, but significant amount of trisose-phsophates is also converted into triacylglycerol in liver cells through the process of de novo lipogenesis (TG) [12]. Although quantitatively far less important than the other pathways of fructose 
disposal, de novo lipogenesis appears to be closely associated with the adverse metabolic effects of fructose.

Because fructose metabolism is not dependent on insulin secretion, at least for its initial steps, and because fructose ingestion causes only a limited rise in glycemia, fructose was initially proposed as a natural substitute of sucrose for diabetic patients. It however became rapidly apparent that an increased dietary intake of fructose had serious adverse metabolic effects in both rodents and humans. Thus it was recognized that a high-fructose intake is associated with increased plasma triglyceride concentrations, hepatic steatosis, impaired glucose tolerance and insulin resistance, and even high blood pressure [4,5].

Besides these metabolic effects, fructose effects on mineral metabolism have also been considered. Fructose forms complexes with metal ions and hence may modulate the intestinal absorption and bioavailability of minerals [13]. Fructose has indeed been reported to decrease copper absorption in rats [14]. A diet containing up to $20 \%$ energy as fructose had however no adverse effect on copper balance in humans [15]. Fructose also increases iron absorption in rats [15] but does not appear to alter zinc bioavailability [16]. The effects of fructose on calcium metabolism have also been documented. The results indicated that rats receiving glucose-sweetened beverages had lower phosphate and calcium intake and increased urinary calcium excretion compared to the rats receiving fructose-sweetened beverages. These results suggest that fructose is not directly involved in the negative association that was observed between sugar intake and bone health [17]. Sweetened beverage consumption however accounts for an important portion of total fructose intake. In some populations, mainly children and teenagers, a high consumption of sweetened beverages may be associated with a lowered intake of milk, and hence, of calcium [18].

Several important questions regarding the role of fructose in the pathogenesis of metabolic diseases remain, however, only partially addressed, as follows.

\section{What are the mechanisms responsible for fructose-induced metabolic alterations?}

There is overwhelming evidence that, in rodents, a high-sucrose or a high-fructose diet will lead to the development of obesity, diabetes, and dyslipidemia, and to a substantial decrease in both liver and muscle insulin sensitivity [19]. Oxidative stress and endoplasmic reticulum stress appear to be involved in these processes [2023]. Furthermore, the adverse metabolic effects observed with high-sucrose diets appear directly related to the fructose component of sucrose [24]. The adverse effects of fructose on glucose metabolism are closely linked to alterations of lipid metabolism. In rats, intrahepatic fat content and blood very low density lipoprotein (VLDL)triacylglycerol concentrations increase within $6 \mathrm{wk}$ of a high-fructose diet, while intramuscular fat content increases within about 3 mo. Interestingly, the development of insulin resistance follows a similar time course: hepatic insulin resistance is observed early after switching to a high-fructose diet, while the appearance of muscle insulin resistance is delayed [19]. This suggests that fructose-induced insulin resistance is closely linked to ectopic lipid deposition and tissue-specific lipotoxicity [25].

In humans, the adverse metabolic effects of fructose are less clearly documented. There is ample evidence that increasing the fructose content of the diet increases plasma triglycerides, through several mechanisms, among which are a stimulation of hepatic de novo lipogenesis [26], and a decreased VLDL-triacylglycerol clearance [27]. Based on animal experiments, an increased VLDL-triacylglycerol secretion is also likely to be involved [28]. The increase in plasma triglyceride induced by fructose is significantly blunted in females, which suggests that female sex hormones may exert a protective effect $[29,30]$. In humans, a high-fructose, hypercaloric diet leads to ectopic fat deposition in liver cells and skeletal muscle in humans already after a 1-wk period [31]. There is strong evidence that fructose decreases hepatic insulin sensitivity in humans [26,32,33], and that a 10wk high-fructose diet impairs glucose homeostasis in overweight individuals [34]; however, few studies have directly evaluated the effect of a high-fructose diet on whole body insulin sensitivity. It has been reported that supplementation with various amounts of fructose for up to 4 wk failed to decrease whole body insulin sensitivity in healthy individuals [31,35]. Whether this may be different in obese insulin-resistant subjects remains to be evaluated. 
In animal models, high-fructose diets almost invariably lead to the concomitant development of excess body fat and insulin resistance; an increased body fat mass, body fat distribution, and ectopic lipid deposition in liver and muscle can all play a role in the development of the metabolic syndrome. In humans, it has been recognized for several decades that abdominal fat distribution is associated with metabolic and cardiovascular diseases [36], and that intravisceral fat contributes much more to insulin resistance than subcutaneous fat [37]. In this regard, the interrelationship between body fat distribution and intrahepatic fat content bears a special interest. Many obese patients indeed do not display significant metabolic disorders and have been coined "healthy obese" or "metabolically fit obese" [38]. When comparing these healthy obese subjects to obese subjects with metabolic complications, it appears that both intravisceral fat and intrahepatic fat content are tightly related with insulin resistance. Furthermore, intrahepatic fat content appears more specifically related to the metabolic syndrome $[39,40]$. In humans, a high-fructose diet has been shown to increase visceral fat [34] and intrahepatic fat [31], which raises the possibility that the effects on hepatic fat metabolism and on visceral fat deposits may be central in the adverse metabolic effects of fructose. Based on these considerations, it is tempting to speculate that a stimulation of hepatic de novo lipogenesis induced by fructose leads to intrahepatic fat deposition, increased VLDL-triacylglycerol secretion, and hepatic insulin resistance; this may also secondarily lead to visceral fat deposition through mechanisms that remain to be determined. With time, the increased plasma VLDL-TG and an inhibition of lipid oxidation induced by a high-fructose diet may favor ectopic fat deposition in muscle, muscle lipotoxicity, and whole body insulin resistance (Fig. 1).

Fructose is also known to increase plasma uric acid, and this effect may be involved in the development of insulin resistance. In rats, fructose-induced hyperuricemia results in inhibition of NO synthase. Because insulininduced glucose utilization involves not only the stimulation of key metabolic pathways in insulin-sensitive cells but also a NO-dependent increase in muscle blood flow [41], it was proposed that inhibition of the vascular effects of insulin by uric acid was involved in fructose-induced insulin resistance. In support of this hypothesis the development of insulin resistance was prevented by lowering uric acid concentrations with an uricosuric agent in fructose-fed rats [42].

Fig. 1. Putative mechanisms linking excess fructose consumption to the metabolic syndrome. In liver cells, fructose stimulates de novo lipogenesis, leading to increased hepatic fatty acids, which can be deposited as ectopic liver fat (hepatic steatosis) or be secreted as VLDL-triacylglycerols. In addition, fructose impairs the extrahepatic clearance of VLDL-triacylglycerols. When excess fructose calories are consumed, this leads to hepatic steatosis and to hyper-triacylglycerolemia, which in turn favors visceral fat accumulation and ectopic lipid deposition in skeletal muscle. The metabolic syndrome develops in the long run as a consequence of hepatic and muscle lipotoxicity and of visceral obesity.

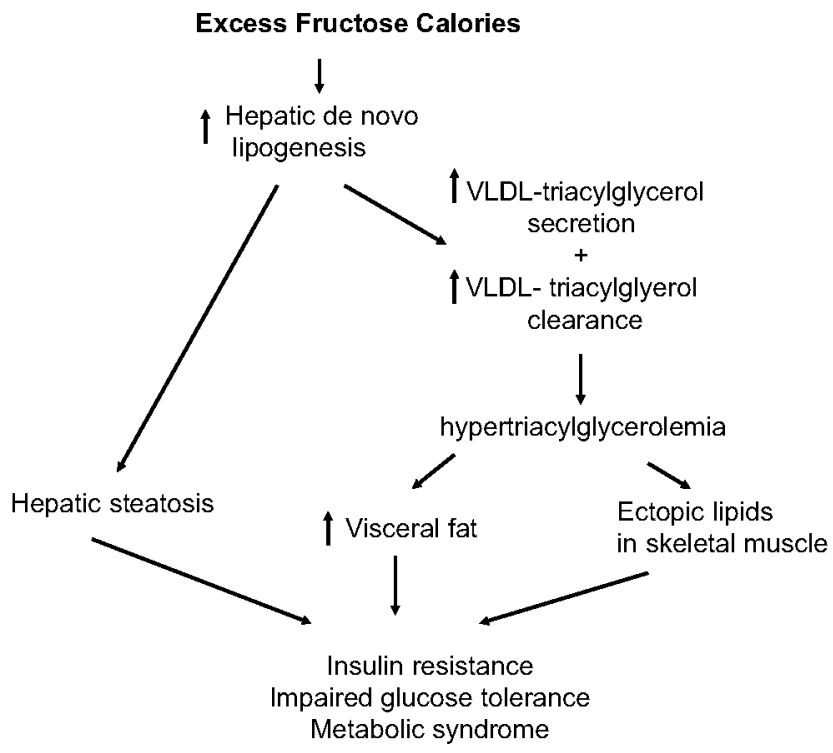




\section{Are the effects of fructose different from those of glucose?}

In our everyday diet, naturally occurring, free fructose (essentially with fruits and honey) is a modest component of energy intake. Furthermore, there is some evidence that consumption of fructose with fruits or honey does not produce the same adverse metabolic effects as added fructose. This may be due to the presence of natural antioxidants and/or dietary fibers with fruits and honey [20,21 ]. The vast majority of fructose in our diet corresponds to added sugars, the two main sources being sucrose (containing 50\% fructose) and HFCS (containing $42 \%-55 \%$ fructose). As a consequence, the intakes of fructose and glucose always vary simultaneously, and therefore, high-fructose consumers are also high-glucose consumers. Few studies have however compared the effects of high-fructose versus high-glucose diets. In rodents, a high-fructose diet was shown to increase the expression of lipogenic genes, to suppress peroxisome proliferator activated receptor-alpha (PPAR- $\alpha$ )-dependent lipid oxidation genes, and to cause intrahepatic fat deposition and hypertriglyceridemia. In contrast, a high-glucose diet also stimulated lipogenic gene expression, but failed to suppress lipid oxidation genes or to produce hepatic steatosis or dyslipidemia [43]. In humans, it has been shown that fructose, when substituted for starch, increases plasma triglycerides [44]. It has also been shown that, in obese hyperinsulinemic women, administration of equivalent amounts of pure fructose, sucrose, and HFCS led to identical increases in plasma triglyceride, although the intake of fructose was about 50\% less with sucrose and HFCS compared to pure fructose [30]. In normal weight and obese women overfed for $4 \mathrm{~d}$ with $50 \%$ glucose or fructose above their energy requirement, de novo lipogenesis was found to be identical under both conditions. There was also no significant difference in plasma glucose, triacylglycerol, or insulin concentrations [45]. In healthy young normal weight subjects, a 6-d overfeeding with $3.5 \mathrm{~g} / \mathrm{kg}$ fat-free mass/d (corresponding roughly to $30 \%$ energy requirements) fructose or glucose increased both VLDL-triacylglycerol concentrations and intrahepatic fat, with large interindividual variations, however [46]. In overweight subjects who received glucose or fructose drinks corresponding to $30 \%$ of their energy requirements with ad libitum food intake, body weight increased to the same extent with both sugars, while impaired glucose tolerance developed only in subjects receiving fructose. Interestingly, fructose significantly increased visceral adipose tissue as estimated by magnetic resonance imaging, while the increase with glucose was of smaller magnitude and failed to reach statistical significance [34].

Because all these experiments involved hypercaloric conditions, one might wonder whether the observed effects can be specifically attributed to sugars or are the mere consequence of hypercaloric feeding. Similar short-term overfeeding experiments were performed with a saturated fat supplementation corresponding to $30 \%$ energy requirements: they demonstrated that fat overfeeding also increased intrahepatic fat content, but failed to increase plasma VLDL-triacylglycerol. Altogether, one may conclude that excess calories, whether as simple sugars or as saturated fat, increases intrahepatic fat content, and that sugars specifically increase plasma VLDLtriglyceride. Fructose however appears to exert this latter effect more potently than glucose. Such short-term experiments remain however difficult to extrapolate to dietary alterations of longer durations, for, with time, significant changes in body composition are likely to occur.

\section{Are the effects of free fructose different from bound fructose?}

In North America, HFCS has replaced a substantial portion of sucrose over the past three decades. The concomitant increases in the HFCS intake and in the prevalence of obesity have raised concern regarding a possible causal role of HFCS [47]. In rodents, feeding a diet rich in HFCS increased body weight and body fat and caused dyslipidemia and insulin resistance. As for fructose, HFCS feeding elicited an endoplasmic reticulum stress response in hepatocytes. These effects of HFCS appear therefore very comparable to those of sucrose $[48,49]$. HFCS differs from sucrose by a slightly higher fructose content, and by providing glucose and fructose as monosaccharides. There is however no evidence that providing fructose as a hexose has different metabolic effects than when fructose is consumed bound to glucose in sucrose. In patients with type 2 diabetes, the glucose and insulin responses to administration of $35 \mathrm{~g}$ of sucrose or HFCS were quite similar [50]. Based on the fact that fructose inhibits less ghrelin and increases less leptin than glucose [51], one may have hypothesized that HFCS would have a different effect than sucrose on these hormones and hence would have a lesser satiating effect. It was however documented that it was not the case, and that HFCS and sucrose produced similar leptin increases and ghrelin suppression in healthy female volunteers [52]. Furthermore, HFCS, sucrose, or equimolar glucose-fructose mixtures elicited similar satiety responses [53] or energy intake at a subsequent meal [54]. There is therefore no hint that the effects of free fructose may differ from those of fructose bound to glucose. 


\section{Do changes in fructose consumption explain the current epidemics of metabolic disorders?}

There is compelling evidence that a hypercaloric, high-fructose diet can induce, not only in animal models, but also in humans, a whole range of metabolic alterations, the most prominent being a disturbance of hepatic lipid metabolism and of plasma lipid profile. This, together with the observation that total sugar and fructose intakes have increased significantly over the past three decades, has led to the speculation that a high-fructose intake may bear a direct, causal effect in the current epidemics of obesity and related metabolic disorders $[47,55]$. Several surveys, using various epidemiologic methods to assess dietary intakes, have consistently reported that total sugar consumption, added sugar intake, and fructose have indeed increased worldwide over the past three decades [56], reviewed in [6]. In the US, average fructose consumption has increased from about $37 \mathrm{~g} / \mathrm{d}$ in the late 1970s [56] to $49 \mathrm{~g} / \mathrm{d}$ in the 1999-2004 period [57]. Not only fructose, but also total energy intake, increased during the same period.

Consumption of sweetened beverages accounts for the major portion of total fructose consumption, the remaining being mainly added sugar. As a result, glucose intake always covaries with fructose intake, and epidemiologic studies cannot differentiate between the effects of fructose per se and those specifically attributable to glucose. In this regard, it is therefore more appropriate to evaluate the potential effect of fructose by comparing the evolutions over time of sweetened beverages and metabolic diseases. While doing so, one has however to keep in mind that sweetened beverage consumption impacts on both sugar consumption and total energy intake at the same time.

Several studies have assessed the relationships between sweetened beverages consumption and energy intake, and a meta-analysis clearly documented that sweetened beverages consumption was associated with an excess energy intake [18]. Many cross-sectional studies have shown a positive association between consumption of sweetened beverages, mainly in teenagers, and body weight [58-65] (reviewed in [66]). Interventional studies further showed that adding sweetened beverages to the usual diet led to an increase in body weight $[67,68]$, while reducing sweetened beverages intake in overweight subjects decreased body weight [69-73]. Several large studies also reported that sweetened beverage consumption increased the risk of developing type 2 diabetes, but this effect was essentially linked to body weight changes [74-76]. A significant association was observed between sweetened beverage consumption and an increased incidence of heart disease. Here again, this was mainly explained by a higher body weight in those consuming sweetened beverages. The relationship nonetheless remained significant after adjusting for body weight and may be explained either by the highglycemic index or by the high-fructose content of sweetened beverages [77]. Finally it was reported that the consumption of sweetened beverages was higher in patients with non-alcoholic steatohepatitis than in healthy controls [78].

\section{Perspectives and conclusions}

There is considerable evidence that a high-fructose intake can indeed produce adverse metabolic alterations, the most prominent ones being an increase in plasma triglycerides, hepatic insulin resistance, and hepatic steatosis. These effects are consistently observed in rodents fed a high-fructose diet and are generally concomitant with an increased body mass. In humans, many of these alterations (hepatic steatosis, hepatic insulin resistance) are observed when fructose is experimentally administered in amounts largely exceeding usual fructose intake, and under hypercaloric conditions. When administered as part of a weight-maintenance diet, fructose can indeed increase plasma triglyceride. A recent meta-analysis [79] concluded that a fructose intake $>50 \mathrm{~g} / \mathrm{d}$ was already associated with altered plasma triglyceride concentrations. Fructose consumption and sweetened beverages are closely linked, and there is overwhelming evidence that sweetened beverage intake favors weight gain and that excess body weight in turn increases the risk of diabetes and coronary heart diseases. It appears therefore sound at this stage to advise limiting consumption of sugar calories to less than $140 \mathrm{kcal} / \mathrm{d}$ for men and $100 \mathrm{kcal} / \mathrm{d}$ for women (corresponding to about one can of sweetened beverage/d), as recently proposed by the American Heart Association [80]. Several important questions remain nonetheless unaddressed, and further studies are clearly required to better delineate the potential adverse metabolic effects of fructose when included in a weightmaintenance, non-hypercaloric diet, to document the interactions between fructose and other nutrients, and to evaluate whether there exist subgroups of individuals (obese insulin-resistant patients, offsprings of patients with type 2 diabetes) in whom the adverse metabolic effects of fructose may possibly be enhanced. 
Published in: Nutrition (2010), vol. 26, pp. 1044-1049

Status: Postprint (Author's version)

\section{Acknowledgments}

The work performed on this topic in the authors' laboratory has been supported by Grants 067787,109737 , and 121995 from the Swiss National Foundation for Science.

\section{References}

[ 1 ] Yudkin J. Dietary carbohydrate and ischemic heart disease. Am Heart J 1963;66:835-6.

[2] Wolf A, Bray GA, Popkin BM. A short history of beverages and how our body treats them. Obes Rev 2008;9:151-64.

[3] White JS. Straight talk about high-fructose corn syrup: what it is and what it ain't. Am J Clin Nutr 2008;88:1716S-21S.

[4] Lê KA TL. Metabolic effects of fructose. Curr Opin Clin Nutr Metabol Care 2007;10:210-4.

[5] Havel PJ. Dietary fructose: implications for dysregulation of energy homeostasis and lipid/carbohydrate metabolism. Nutr Rev 2005;63: 133-57.

[6] Tappy L, Le KA. Metabolic effects of fructose and the worldwide increase in obesity. Physiol Rev 2010;90:23-46.

[7] Douard V, Ferraris RP. Regulation of the fructose transporter GLUT5 in health and disease. Am J Physiol Endocrinol Metab 2008;295:E227-37.

[8] Corpe CP, Burant CF, Hoekstra JH. Intestinal fructose absorption: clinical and molecular aspects. J Pediatr Gastroenterol Nutr $1999 ; 28: 364-74$

[9] Kneepkens CM, Vonk RJ, Fernandes J. Incomplete intestinal absorption of fructose. Arch Dis Child 1984;59:735-8.

[10] Ravich WJ, Bayless TM, Thomas M. Fructose: incomplete intestinal absorption in humans. Gastroenterology 1983;84:26-9.

[11] Mayes PA. Intermediary metabolism of fructose. Am J Clin Nutr 1993;58(suppl):754S-65S.

[12] Parks EJ, Skokan LE, Timlin MT, Dingfelder CS. Dietary sugars stimulate fatty acid synthesis in adults. J Nutr 2008;138:1039-46.

[13] O'Dell BL Fructose and mineral metabolism. Am J Clin Nutr 1993;58: 771S-8S.

[14] Johnson MA. Interaction of dietary carbohydrate, ascorbic acid and copper with the development of copper deficiency in rats. J Nutr 1986;116:802-15.

[15] Reiser S, Smith JC Jr, Mertz W, Holbrook JT, Scholfield DJ, Powell AS, et al. Indices of copper status in humans consuming a typical American diet containing either fructose or starch. Am J Clin Nutr 1985;42:242-51.

[ 16] Smith JC Jr, Failla ML, Fields M, Rose A, Seidel K. Lack of an effect of dietary fructose on severity of zinc deficiency in rats. J Nutr 1987;117:1443-6.

[17] Tsanzi E, Light HR, Tou JC. The effect of feeding different sugar-sweetened beverages to growing female Sprague-Dawley rats on bone mass and strength. Bone 2008;42:960-8.

[18] Vartanian LR, Schwartz MB, Brownell KD. Effects of soft drink consumption on nutrition and health: a systematic review and metaanalysis. Am J Public Health 2007;97:667-75.

[19] Bizeau ME, Pagliassotti MJ. Hepatic adaptations to sucrose and fructose. Metab Clin Exp 2005;54:1189-201.

[20] Busserolles J, Gueux E, Rock E, Demigne C, Mazur A, Rayssiguier Y. Oligo-fructose protects against the hypertriglyceridemic and prooxidative effects of a high fructose diet in rats. J Nutr 2003;133:1903-8.

[21 ] Busserolles J, Gueux E, Rock E, Mazur A, Rayssiguier Y. Substituting honey for refined carbohydrates protects rats from hypertriglyceridemic and prooxidative effects of fructose. J Nutr 2002;132:3379-82.

[22] Wei Y, Wang D, Pagliassotti MJ. Fructose selectively modulates c-jun N-terminal kinase activity and insulin signaling in rat primary hepatocytes. J Nutr 2005;135:1642-6.

[23] Mellor K, Ritchie RH, Meredith G, Woodman OL, Morris MJ, Delbridge LM. High-fructose diet elevates myocardial superoxide generation in mice in the absence of cardiac hypertrophy. Nutrition 2010;26:842-8. 
Published in: Nutrition (2010), vol. 26, pp. 1044-1049

Status: Postprint (Author's version)

[24] Thresher JS, Podolin DA, Wei Y, Mazzeo RS, Pagliassotti MJ. Comparison of the effects of sucrose and fructose on insulin action and glucose tolerance. Am J Physiol Regul Int Comp Physiol 2000;279:R1334-440.

[25] Unger RH. Minireview: weapons of lean body mass destruction: the role of ectopic lipids in the metabolic syndrome. Endocrinology 2003;144: 5159-65.

[26] Faeh D, Minehira K, Schwarz J, Periasami R, Seongus P, Tappy L. Effect of fructose overfeeding and fish oil administration on hepatic de novo lipo-genesis and insulin sensitivity in healthy males. Diabetes 2005;54:1907-13.

[27] Chong MF, Fielding BA, Frayn KN. Mechanisms for the acute effect of fructose on postprandial lipemia. Am J Clin Nutr 2007;85:151120

[28] Taghibiglou C, Carpentier A, Van Iderstine SC, Chen B, Rudy D, Aiton A, et al. Mechanisms of hepatic very low density lipoprotein overproduction in insulin resistance. Evidence for enhanced lipoprotein assembly, reduced intracellular ApoB degradation, and increased microsomal triglyceride transfer protein in a fructose-fed hamster model. J Biol Chem 2000;275:8416-25.

[29] Couchepin C, Le KA, Bortolotti M, da Encarnacao JA, Oboni JB, Tran C, et al. Markedly blunted metabolic effects of fructose in healthy young female subjects compared with male subjects. Diabetes Care 2008;31:1254-6.

[30] Stanhope KL, Griffen SC, Bair BR, Swarbrick MM, Keim NL, Havel PJ. Twenty-four-hour endocrine and metabolic profiles following consumption of high-fructose corn syrup-, sucrose-, fructose-, and glucose-sweetened beverages with meals. Am J Clin Nutr 2008;87:1194203

[31 ] Le KA, Ith M, Kreis R, Faeh D, Bortolotti M, Tran C, et al. Fructose over-consumption causes dyslipidemia and ectopic lipid deposition in healthy subjects with and without a family history of type 2 diabetes. Am J Clin Nutr 2009;89:1760-5.

[32] Schwarz J-M, Schutz Y, Piolino V, Schneider H, Felber J-P, Jéquier E. Ther-mogenesis in obese women: effect of fructose vs glucose added to a meal. Am J Physiol 1992;262:E394-401.

[33] Dirlewanger M, Schneiter P, Jéquier E, Tappy L. Effects of fructose on hepatic glucose metabolism in humans. Am J Physiol 200;279:E907-11.

[34] Stanhope KL, Schwarz JM, Keim NL, Griffen SC, Bremer AA, Graham JL, et al. Consuming fructose-sweetened, not glucosesweetened, beverages increases visceral adiposity and lipids and decreases insulin sensitivity in overweight/obese humans. J Clin Invest 2009;119:1322-34

[35] Le KA FD Stettler R, Ith M, Kreis R, Vermathen P, Boesch C, et al. A 4-wk high-fructose diet alters lipid metabolism without affecting insulin sensitivity or ectopic lipids in healthy humans. AmJ Clin Nutr 2006;84:1374-9.

[36] Vague J. The degree of masculine differentiation of obesities: a factor determining predisposition to diabetes, atherosclerosis, gout, and uric calculous disease. AmJ Clin Nutr 1956;4:20-34

[37] Klein S, Fontana L, Young VL, Coggan AR Kilo C, Patterson BW, et al. Absence of an effect of liposuction on insulin action and risk factors for coronary heart disease. N Engl J Med 2004;350:2549-57.

[38] Wildman RP. Healthy obesity. Curr Opin Clin Nutr Metab Care 2009;12:438-43.

[39] Stefan N, Kantartzis K, Machann J, Schick F, Thamer C, Rittig K, et al. Identification and characterization of metabolically benign obesity in humans. Arch Intern Med 2008;168:1609-16.

[40] Fabbrini E, Magkos F, Mohammed BS, Pietka T, Abumrad NA, Patterson BW, et al. Intrahepatic fat, not visceral fat, is linked with metabolic complications of obesity. Proc Natl Acad Sci USA 2009;106:15430-5.

[41] Baron AD, Steinberg HO, Chaker H, Leaming R, Johnson A, Brechtel G. Insulin-mediated skeletal muscle vasodilation contributes to both insulin sensitivity and responsiveness in lean humans. J Clin Invest 1995;96: 786-92.

[42] Nakagawa T, Hu H, Zharikov S, Tuttle KR, Short RA, Glushakova O, et al. A causal role for uric acid in fructose-induced metabolic syndrome. Am J Physiol Renal Physiol 2006;290:F625-31.

[43] Roglans N, Vila L, Farre M, Alegret M, Sanchez RM, Vazquez-Carrera M, et al. Impairment of hepatic Stat-3 activation and reduction of PPARalpha activity in fructose-fed rats. Hepatology 2007;45:778-88.

[44] Hollenbeck CB. Dietary fructose effects on lipoprotein metabolism and risk for coronary artery disease. Am J Clin Nutr 1993;58(suppl):800S-9S

[45] McDevitt RM, Bott SJ, Harding M, Coward WA, Bluck LJ, Prentice AM. De novo lipogenesis during controlled overfeeding with sucrose or glucose in lean and obese women. Am J Clin Nutr 2001;74:737-46. 
Published in: Nutrition (2010), vol. 26, pp. 1044-1049

Status: Postprint (Author's version)

[46] Ngo-sock E, Lê K-A, Ith M, Kreis R Boesch C, Tappy L Effects of a short-term overfeeding with fructose or glucose in healthy young males. Br J Nutr 2010;103:939-43.

[47] Bray GA, Nielsen SJ, Popkin BM. Consumption of high-fructose corn syrup in beverages may play a role in the epidemic of obesity. Am J Clin Nutr 2004;79:537-43.

[48] Tetri LH, Basaranoglu M, Brunt EM, Yerian LM, Neuschwander-Tetri BA. Severe NAFLD with hepatic necroinflammatory changes in mice fed trans fats and a high-fructose corn syrup equivalent. Am J Physiol Gastrointest Liver Physiol 2008;295:G987-95.

[49] Collison KS, Saleh SM, Bakheet RH, Al-Rabiah RK, Inglis AL, Makhoul NJ, et al. Diabetes of the liver: the link between nonalcoholic fatty liver disease and HFCS-55. Obesity (Silver Spring) 2009;17:2003-13.

[50] Akgun S, Ertel NH. The effects of sucrose, fructose, and high-fructose corn syrup meals on plasma glucose and insulin in non-insulindependent diabetic subjects. Diabetes Care 1985;8:279-83.

[51] Teff KL, Elliott SS, Tschöp M, Kieffer TJ, Rader D, Heiman M, et al. Dietary fructose reduces circulating insulin and leptin, attenuates postprandial suppression of ghrelin, and increases triglycerides in women. J Clin Endocrinol Metab 2004;89:2963-72.

[52] Melanson KJ, Zukley L, Lowndes J, Nguyen V, Angelopoulos TJ, Rippe JM. Effects of high-fructose corn syrup and sucrose consumption on circulating glucose, insulin, leptin, and ghrelin and on appetite in normal-weight women. Nutrition 2007;23:103-12

[53] Akhavan T, Anderson GH. Effects of glucose-to-fructose ratios in solutions on subjective satiety, food intake, and satiety hormones in young men. Am J Clin Nutr 2007;86:1354-63.

[54] Soenen S, Westerterp-Plantenga MS. No differences in satiety or energy intake after high-fructose corn syrup, sucrose, or milk preloads. Am J Clin Nutr 2007;86:1586-94.

[55] Johnson RJ, Segal MS, Sautin Y, Nakagawa T, Feig DI, Kang DH, et al. Potential role of sugar (fructose) in the epidemic of hypertension, obesity and the metabolic syndrome, diabetes, kidney disease, and cardiovascular disease. Am J Clin Nutr 2007;86:899-906.

[56] Park YK, Yetley EA. Intakes and food sources of fructose in the United States. Am J Clin Nutr 1993;58(suppl):737S-47S.

[57] Marriott BP, Cole N, Lee E. National estimates of dietary fructose intake increased from 1977 to 2004 in the United States. J Nutr 2009;139: 1228S-35S

[58] Troiano RP, Briefel RR, Carroll MD, Bialostosky K. Energy and fat intakes of children and adolescents in the united states: data from the national health and nutrition examination surveys. Am J Clin Nutr 2000;72: 1343S-53S

[59] Giammattei J, Blix G, Marshak HH, Wollitzer AO, Pettitt DJ. Television watching and soft drink consumption: associations with obesity in 11- to 13-year-old schoolchildren. Arch Pediatr Adolesc Med 2003;157:882-6.

[60] Liebman M, Pelican S, Moore SA, Holmes B, Wardlaw MK, Melcher LM, et al. Dietary intake, eating behavior, and physical activityrelated determinants of high body mass index in rural communities in Wyoming, Montana, and Idaho. Int J Obes Relat Metab Disord 2003;27:684-92.

[61] Ludwig DS, Peterson KE, Gortmaker SL Relation between consumption of sugar-sweetened drinks and childhood obesity: a prospective, observational analysis. Lancet 2001;357:505-8

[62] Berkey CS, Rockett HR, Field AE, Gillman MW, Colditz GA. Sugar-added beverages and adolescent weight change. Obes Res 2004; $12: 778-88$

[63] Welsh JA, Cogswell ME, Rogers S, Rockett H, Mei Z, Grummer-Strawn LM. Overweight among low-income preschool children associated with the consumption of sweet drinks: Missouri, 1999-2002. Pediatrics 2005;115:e223-9.

[64] Schulze MB, Manson JE, Ludwig DS, Colditz GA, Stampfer MJ, Willett WC, et al. Sugar-sweetened beverages, weight gain, and incidence of type 2 diabetes in young and middle-aged women. JAMA 2004;292:927-34.

[65] Bandini LG, Vu D, Must A, Cyr H, Goldberg A, Dietz WH. Comparison of high-calorie, low-nutrient-dense food consumption among obese and non-obese adolescents. Obes Res 1999;7:438-43.

[66] Drewnowski A BF. Liquid calories, sugar, and body weight. Am J Clin Nutr 2007;85:651-61.

[67] Tordoff MG, Alleva AM. Effect of drinking soda sweetened with aspartame or high-fructose corn syrup on food intake and body weight. Am J Clin Nutr 1990;51:963-9.

[68] Raben A, Vasilaras TH, Moller AC, Astrup A. Sucrose compared with artificial sweeteners: different effects on ad libitum food intake and body weight after 10 wk of supplementation in overweight subjects. Am J Clin Nutr 2002;76:721-9. 
Published in: Nutrition (2010), vol. 26, pp. 1044-1049

Status: Postprint (Author's version)

[69] Rothacker DQ, Staniszewski BA, Ellis PK. Liquid meal replacement vs traditional food: a potential model for women who cannot maintain eating habit change. J Am Diet Assoc 2001 ; 101:345-7.

[70] Ditschuneit HH, Flechtner-Mors M, Johnson TD, Adler G. Metabolic and weight-loss effects of a long-term dietary intervention in obese patients. Am J Clin Nutr 1999;69:198-204.

[71 ] Yip I, Go VL, DeShields S, Saltsman P, Bellman M, Thames G, et al. Liquid meal replacements and glycemic control in obese type 2 diabetes patients. Obes Res 2001;9(suppl 4):341S-7S

[72] Ashley JM, St Jeor ST, Perumean-Chaney S, Schrage J, Bovee V. Meal replacements in weight intervention. Obes Res 2001;9(suppl 4):312S-20S

[73] Ebbeling CB, Feldman HA, Osganian SK, Chomitz VR, Ellenbogen SJ, Ludwig DS. Effects of decreasing sugar-sweetened beverage consumption on body weight in adolescents: a randomized, controlled pilot study. Pediatrics 20036; 117:673-80.

[74] Bazzano LA, Li TY, Joshipura KJ, Hu FB. Intake of fruit, vegetables, and fruit juices and risk of diabetes in women. Diabetes Care 2008;31:1311-7.

[75] Montonen J, Jarvinen R, Knekt P, Heliovaara M, Reunanen A. Consumption of sweetened beverages and intakes of fructose and glucose predict type 2 diabetes occurrence. J Nutr 2007;137:1447-54.

[76] Palmer JR, Boggs DA, Krishnan S, Hu FB, Singer M, Rosenberg L. Sugar-sweetened beverages and incidence of type 2 diabetes mellitus in African American women. Arch Intern Med 2008;168:1487-92.

[77] Fung TT, Malik V, Rexrode KM, Manson JE, Willett WC, Hu FB. Sweetened beverage consumption and risk of coronary heart disease in women. Am J Clin Nutr 2009;89:1037-42.

[78] Assy N, Nasser G, Kamayse I, Nseir W, Beniashvili Z, Djibre A, et al. Soft drink consumption linked with fatty liver in the absence of traditional risk factors. Can J Gastroenterol 2008;22:811-6.

[79] Livesey G, Taylor R. Fructose consumption and consequences for glycation, plasma triacylglycerol, and body weight: meta-analyses and meta-regression models of intervention studies. Am J Clin Nutr 2008;88: 1419-37.

[80] Johnson RK, Appel LJ, Brands M, Howard BV, Lefevre M, Lustig RH, et al. Dietary sugars intake and cardiovascular health. A Scientific Statement from the American Heart Association. Circulation 2009;120:1011-20. 